\title{
Recent Research at GFDL on Surface Temperature Trends and Simulations of Tropical Cyclone Activity in the Indian Ocean Region
}

\author{
Thomas R. Knutson*, Fanrong Zeng, Andrew Wittenberg, \\ Hyeong-Seog Kim, Joseph Sirutis, Morris Bender, \\ Ming Zhao and Robert Tuleya \\ Geophysical Fluid Dynamics Laboratory/NOAA \\ Princeton, New Jersey, U.S.A. \\ *e-mail: tom.knutson@noaa.gov
}

\section{Introduction and Overview}

In this extended abstract, we report on progress in two areas of research at GFDL relating to Indian Ocean regional climate and climate change. The first topic is an assessment of regional surface temperature trends in the Indian Ocean and surrounding region. Here we illustrate the use of a multi-model approach (CMIP3 or CMIP5 model ensembles) to assess whether an anthropogenic warming signal has emerged in the historical data, including identification of where the observed trends are consistent or not with current climate models. Trends that are consistent with All Forcing runs but inconsistent with Natural Forcing Only runs are ones which we can attribute, at least in part, to anthropogenic forcing.

This topic is quite relevant to the topic of Indian Ocean tropical cyclone (TC) activity, since long-term sea surface temperature warming could be an important environmental change for Indian Ocean tropical cyclones. The second topic in our abstract is a status report on our attempts to dynamically simulate Indian Ocean tropical cyclone activity for the current climate using observed SSTs alone as input to the model. We adopt a two-step procedure, which includes a second dynamical downscaling step - which is an attempt to produce a realistic simulation of very intense tropical cyclone activity. The inputs to the higher resolution model are storm cases from a 27-yr simulation of a global model that used prescribed interannual varying observed SSTs as input. 


\section{Assessment of Regional Surface Temperature Trends in the Indian Ocean/Southern Asia Region}

Previous studies have documented a pronounced SST warming signal in the Indian Ocean and western Pacific warm pool region over the past century (Knutson et al., 1999; Karoly and Wu, 2005; Knutson et al., 2006; Xie et al., 2010). Here we have reassessed this warming signal using: (i) data updated through more recent years (through 2010); (ii) a recently updated combined SST and land temperature data set from the UK Meteorological Office (HadCRUT4); (iii) multi-model (CMIP5) estimates of internal variability and the historical response to anthropogenic and natural radiative forcing changes ( $\sim 1860$ to present); and (iv) analysis of individual seasons as well as annual means. Further details of the methodology and an analysis of the internal variability simulations are contained in Knutson et al. (2013).

Figure 1 shows time series of observed and model-simulated SST for the Indian Ocean region (north of $30^{\circ} \mathrm{S}$ ). The orange and blue lines in the panels depict individual model runs from All Forcing (orange) or Natural Forcing Only (blue) historical runs of several CMIP5 models. "All Forcing" refers to runs that have both natural (e.g., solar variability, volcanic aerosols) and anthropogenic (e.g., well-mixed greenhouse gases, ozone, anthropogenic aerosols, and land use change) forcing agents. Dark red and dark blue lines in Fig. 1 are multi-model ensemble means where each individual model is given

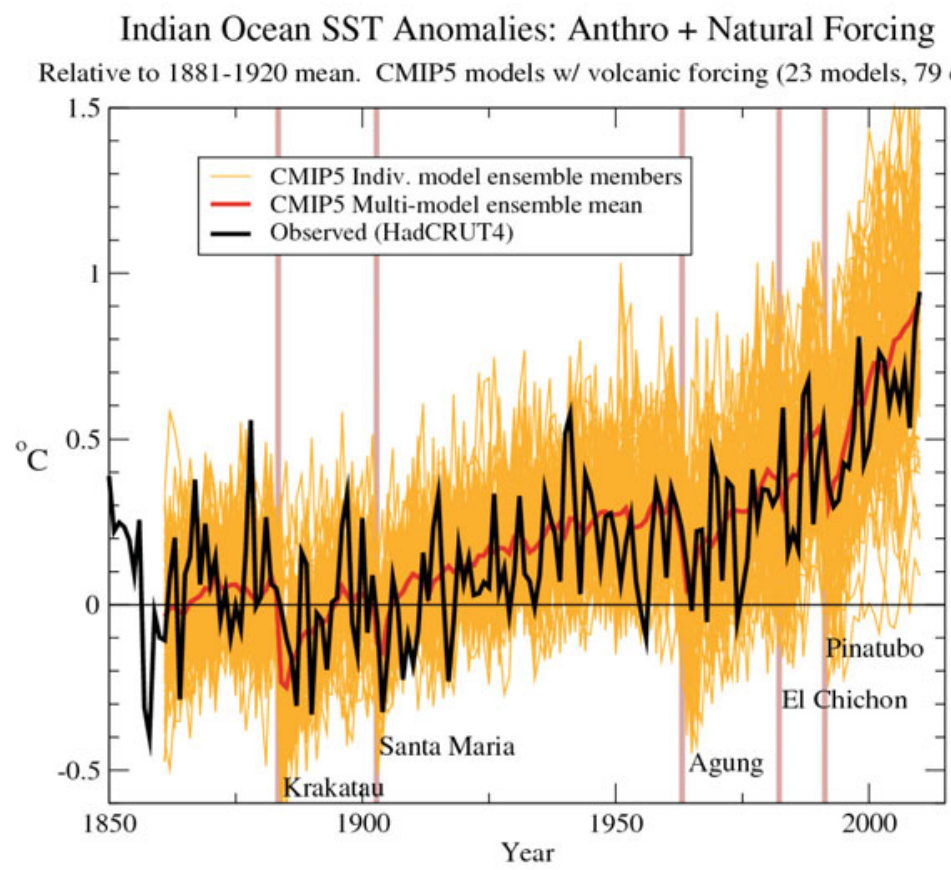

(a) 


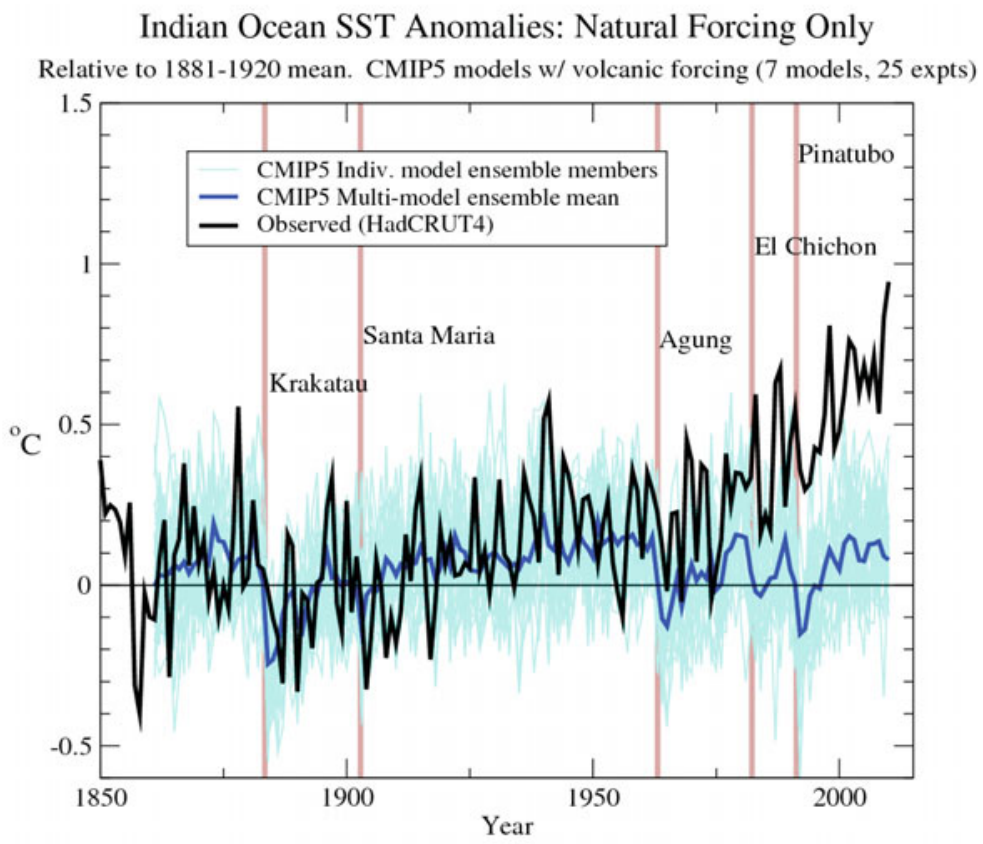

(b)

Fig. 1: Time series of Indian Ocean mean sea surface temperature (SST) anomalies from observations (HadCRUT4; black curves) in degrees Celsius. CMIP5 $20^{\text {th }}$ century historical runs are shown (orange and blue curves) in degrees Celsius. The "All Forcing" historical runs in (a) include 79 experiments across 23 different CMIP5 models. The red curves show the multi-model ensemble means, which were computed by weighting each model equally (as opposed to each individual model run equally). The "Natural Forcing Only" historical runs in (b) are based on seven CMIP5 models (25 runs) that had runs extending through 2010. Each individual series has been re-centred so that the mean value for the years 1881-1920 is zero. Model data were masked with the observed spatially and temporally evolving missing data mask.

equal weight in the average regardless of the number of ensemble members that it contributes to the sample. The observations show a clear warming signal that is fairly consistent with the All Forcing runs, but clearly inconsistent with Natural Forcing Only runs.

Model-observational consistency can be assessed at least qualitatively in Fig. 1. However, Fig. 2 illustrates how the consistency can be assessed more quantitatively for a set of seven CMIP5 models. As described in the caption, we use model control runs to build error bars for the model simulated trends (the trend values plotted in the figure are for trends with varying start dates, but all ending in 2010). Here we assume that the internal variability is not affected by the forcing so that the control run variability is still applicable to confidence intervals for the forced runs. The black-shaded region shows an 


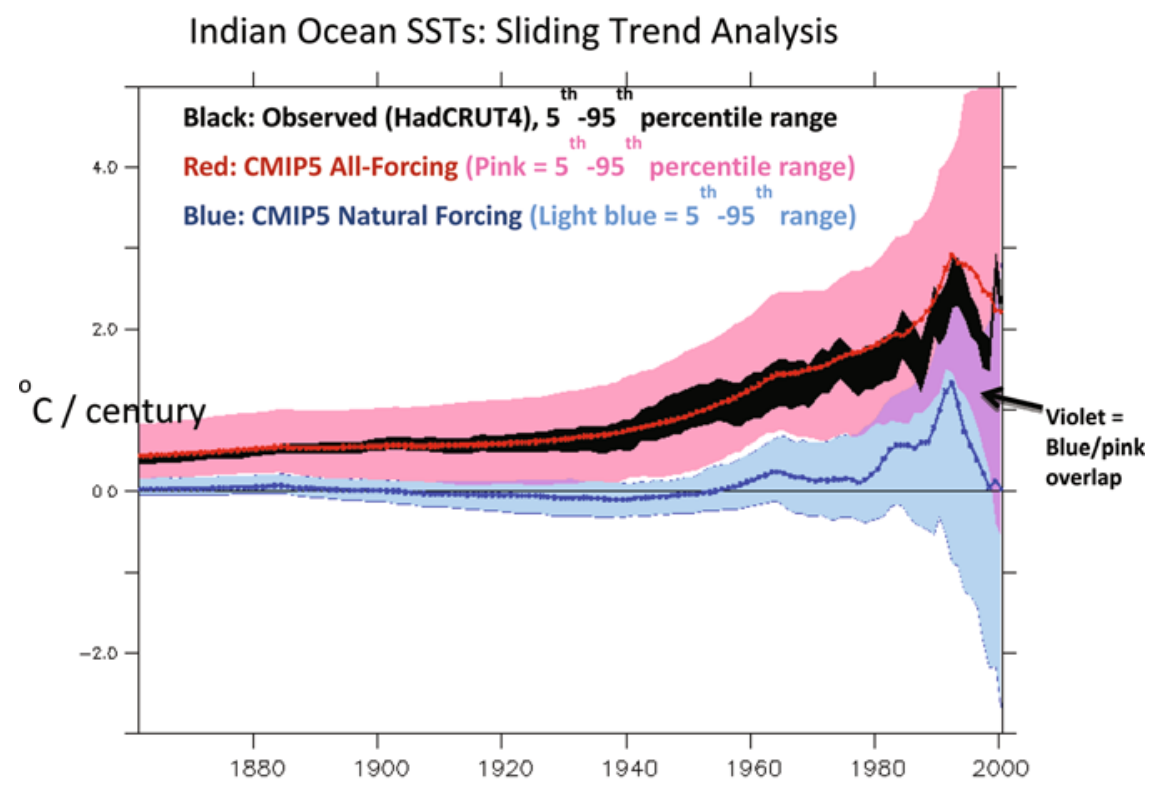

Starting year of trend (all trends ending in 2010)

Fig. 2: Trends $\left({ }^{\circ} \mathrm{C} / 100 \mathrm{yr}\right)$ in area-averaged annual-mean Indian Ocean SST (north of $30^{\circ} \mathrm{S}$ ) are shown as a function of starting year, with all trends ending in 2010 . The black curve shows trends from observations (HadCRUT4), where observational uncertainty is depicted as a range showing the $5^{\text {th }}$ to $95^{\text {th }}$ percentile ranges of trends obtained using the 100-member HadCRUT4 ensemble. The red curve shows ensemble mean trends from the All Forcing runs of seven CMIP5 models. The dark blue curve shows ensemble mean trends for Natural Forcing Only runs extending to 2010. The different models are weighted equally for the multi-model ensemble mean trends, regardless of the number of ensemble members they contributed. The pink shading shows the $5^{\text {th }}$ to $95^{\text {th }}$ percentile range of the distribution of trends obtained by combining random samples from each of the seven CMIP5 model control runs with the corresponding model's ensemble-mean forced trend (All Forcing runs) to create a total multi-model distribution of trends that reflects uncertainty in both the forced response (i.e., the spread among the different model ensemble means) and the influence of internal climate variability (as estimated from the model control runs). The blue-shaded region shows the same, but for Natural Forcing Only runs. Violet shading indicates where the pink- and blue-shaded regions overlap. The seven-CMIP5-model subset used here includes: CanESM2, CNRM-CM5, CSIRO-Mk3-6-0, FGOALS-g2, HadGEM2-ES, IPSL-CM5A-LR, and NorESM1-M.

assessment of the observational uncertainty, which is not trivial, but is much smaller than the uncertainty due to the spread of model results (forcing response and internal variability). When the observed trend (black-shaded region) lies outside of the blue shaded region, the trend is termed "detectable" (i.e., significantly different from natural forcing runs). Trends are detectable for 
start dates up into the late 1980 s according to the results shown. When the black region lies within the pink (or violet) shaded regions, the observed trend is termed "consistent" with the All Forcing runs. This is the case for all start dates shown. When the observed trend is both detectable and consistent with the All Forcing (or if it is significantly greater than the All Forcing trend), we term this a case of a detectable anthropogenic signal, where anthropogenic forcing has contributed, at least in part, to the observed trend. This is the case for trends with start dates up into the late 1980s. In short, a detectable anthropogenic warming is clearly present in the Indian Ocean SST data, according to our model assessment.

What is described for Fig. 2 above is a categorization of the observed trends. This same categorization approach can be applied at the level of individual model grid points. Specifically, for a given start year of a trend to 2010, the observed trend can be categorized as: (i) no detectable trend, (ii) detectable warming that is less than simulated, (iii) detectable warming that is consistent with All Forcing runs (i.e., attributable and consistent anthropogenic warming), or (iv) detectable warming that is greater than in the All Forcing runs (i.e., attributable anthropogenic warming that is greater than simulated). Figure 3 shows the mapped results of such an analysis for the trends in annual mean data over the period 1901-2010. The map indicates that the IPCC AR5 (CMIP5) historical All Forcing runs have a warming trend in the Indian Ocean since 1900 that is similar to that observed. The categorization assessment indicates that there is some tendency for the model ensemble to simulate too small a warming rate since 1901 in the North Indian Ocean (dark red shading), and too high a warming rate in parts of the South Indian Ocean within 30 degrees of the equator (yellow-orange shading). Note that there is at least a detectable warming trend over almost the entire Indian Ocean since 1901, according to this analysis. Much of this warming is either consistent with (red) or exceeds (dark red) the warming in the All Forcing ensemble, and is inconsistent with Natural Forcing only, indicating that a detectable anthropogenic trend is very likely present in the data according to our analysis. This anthropogenic warming signal also extends over the Indian subcontinent and parts of south and southeast Asia.

Figure 4 shows the results of doing a similar trend categorization analysis for individual three-month seasons (i.e., December-February; March-May; JuneAugust; and September-November). The under-prediction of the warming trend in the All Forcing runs is most pronounced in the boreal summer (June-August) and fall (September-November) seasons. Even with the reduced data associated with doing a seasonal analysis, an anthropogenic warming trend contribution is still detectable over most of the Indian Ocean region (red or dark red shading), and over much of the Indian subcontinent, except for the March-May season and to some extent June-August. 


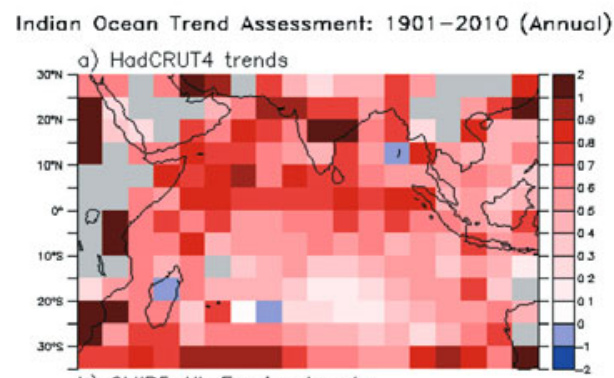

b) CMIP5 All-Forcing trends
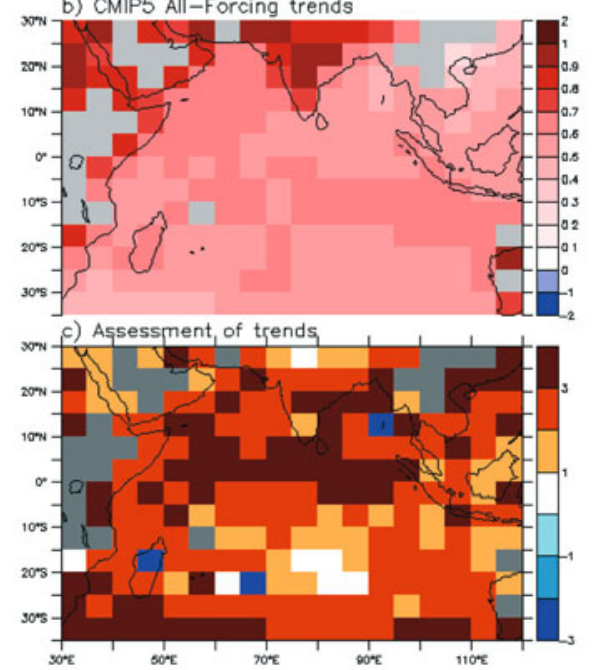

Assessment of trends:

Attrib. anthropogenic warming but $>$ simulated Attrib. \& consistent anthropogenic warming

Detectable warming: < simulated

No detectable trend

Detectable cooling: $<$ simulated

Attributable anthropogenic cooling

Detectable cooling: > simulated

Fig. 3: Analysis of surface temperature trends (1901-2010) for annual mean data from: (a) HadCRUT4 observations; (b) CMIP5 seven-model ensemble mean (All Forcing experiments). Unit: degrees C per $100 \mathrm{yr}$. In (c) the observed trend is assessed in terms of the multi-model ensemble mean trends and variability in the historical forcing and control runs (CMIP5). Specifically, observed trends are compared with simulated trends from the seven CMIP5 models that have both All Forcing and with Natural Forcing Only runs extending to 2010. The different colours in (c) depict different categories of assessment result; the categories are listed in the legend beside the panel and discussed in the text.

\section{Summary}

In short, we find that the Indian Ocean region is the one characterized by a detectable anthropogenic surface warming signal according to the model-based assessment presented here. Owing to this characteristic, the Indian Ocean is therefore a region where we might anticipate relatively earlier detection of SST-related climate change impacts, including changes in tropical cyclone activity, compared with other ocean basins. 
a) December-February

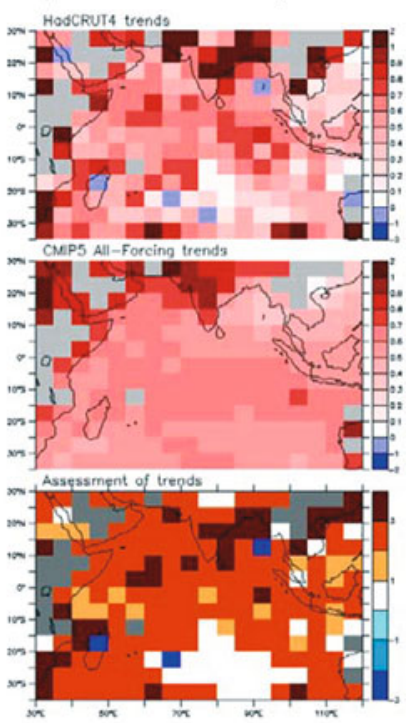

b) March-May

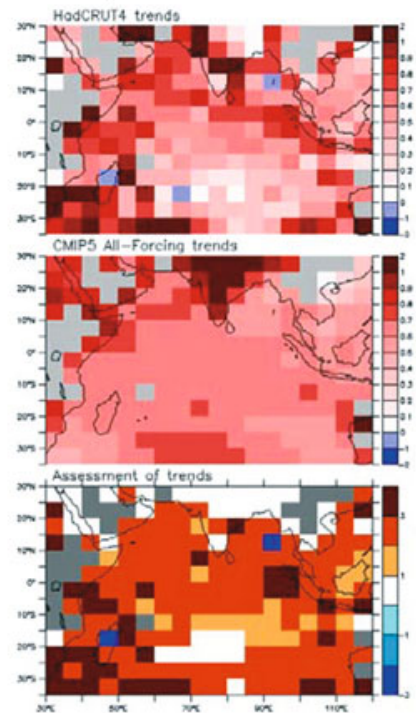

d) September-November
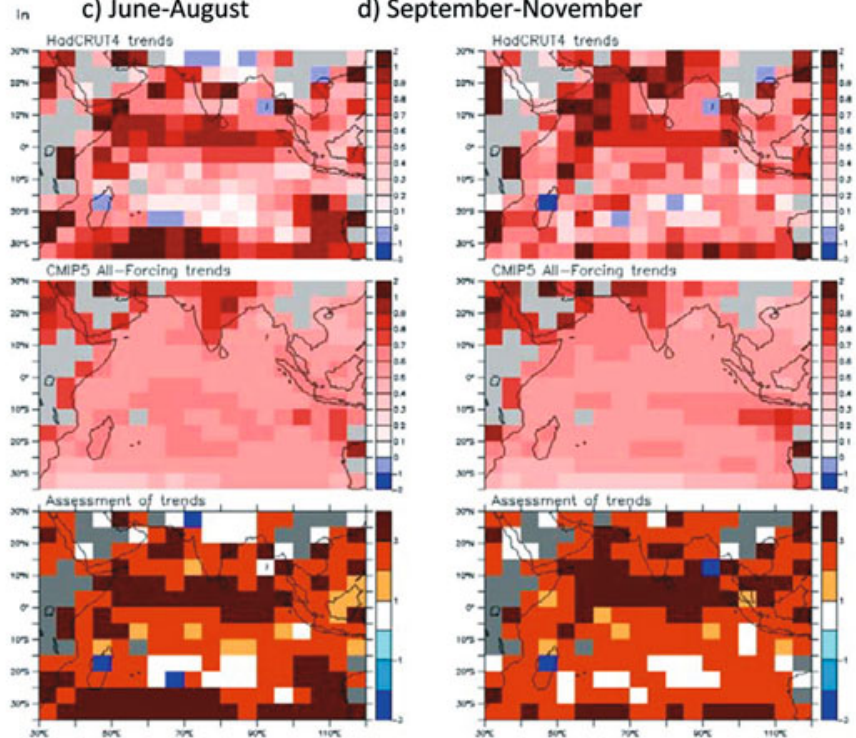

Attrib. anthropogenic. warming but $>$ simulated Attrib. \& consistent anthropogenic warming Detect. warming: < simulated No detectable trend

Detect. cooling: < simulated

Attributable anthropogenic cooling

Detect. cooling: > simulated

Fig. 4: This figure has the same layout of panels as in Fig. 3 but shown separately for the (a) Dec.-Feb.; (b) Mar.-May; (c) June-Aug.; and (d) Sept.-Nov. seasons. 
a) $1901-2010$ (Dec-Feb)

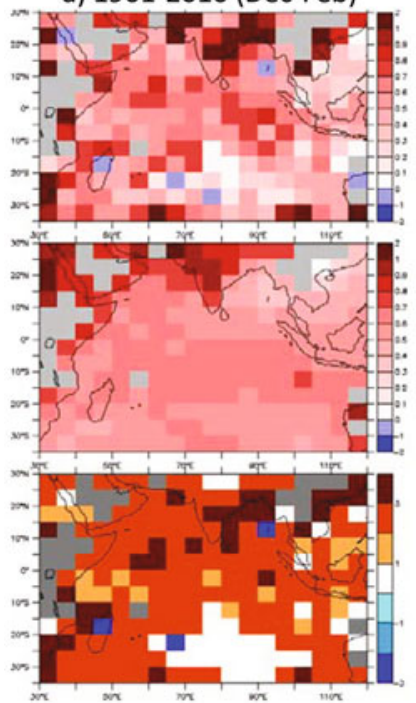

c) $1901-2010$ (June-Aug.)
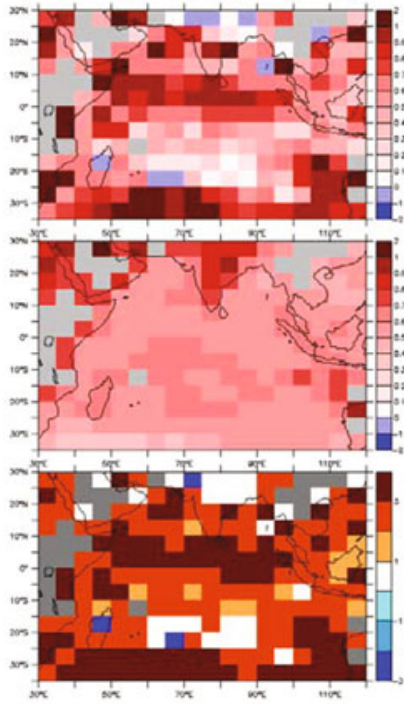

b) $1901-2010$ (Mar.-May)

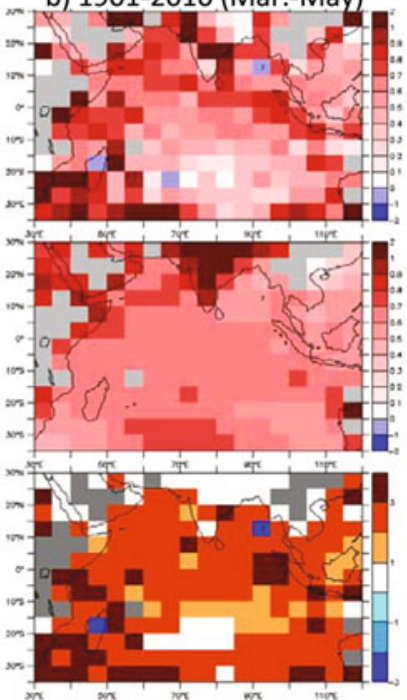

d) $1901-2010$ (Sept.-Nov.)
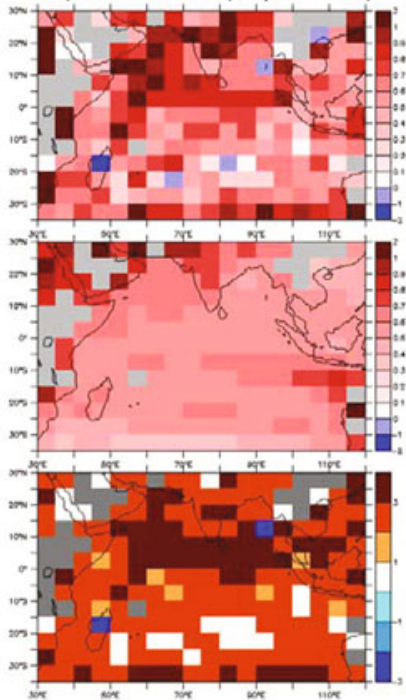

Attrib. anthropogenic warming but > simulated

Attrib. \& consistent anthropogenic warming

Detectable warming: $<$ simulated

No detectable trend

Detectable cooling: < simulated

Attributable anthropogenic cooling

Detectable cooling: > simulated

Fig. 4 (Contd): This figure has the same layout of panels as in

Fig. 3 but shown separately for the (a) Dec.-Feb.; (b) Mar.-May; (c) June-Aug.; and (d) Sept.-Nov. seasons. 


\section{Simulations of Northern Indian Ocean Tropical Cyclone Activity}

We are exploring several methods to simulate TC activity in the Indian Ocean region using dynamical models. Our starting point for the results described here is a global atmospheric model forced by observed time-varying SSTs, which is used to simulate and assess the frequency of tropical cyclones. Zhao et al. (2009) showed that by using such a model with a horizontal grid scale of $50 \mathrm{~km}$, the frequency and interannual variability of tropical cyclones with intensities above a threshold of $33 \mathrm{~m} / \mathrm{s}$ are simulated quite realistically, especially in the Atlantic basin, but also in the Northwest Pacific basin. However, as seen in Fig. 5, the simulation for the North Indian Ocean is not as close to observed as in the Atlantic, with particular too many storms simulated with winds exceeding $33 \mathrm{~m} / \mathrm{s}$ in the Arabian Sea and too few in the Bay of Bengal.

As a second downscaling step, we take each of the individual tropical cyclones (winds exceeding $17 \mathrm{~m} / \mathrm{s}$ ) from the Zhao et al. (2009) simulation and downscale those storm cases into the GFDL hurricane model using the models and approach described in Bender et al. (2010). (Actually we use here a slightly modified version of the Zhao et al. global model that has quite similar simulation characteristics to the original one in Zhao et al. 2009). This allows us to examine the simulated vs. observed distribution of more intense tropical cyclones in the basin using the downscaling framework. The GFDL hurricane model has a grid-spacing over five times as small as in the original global model (as fine as $9 \mathrm{~km}$ ) and also includes dynamical ocean coupling to simulate the potentially significant impact of cold waves beneath intense tropical cyclones.

The global model simulates too many tropical cyclones over the Arabian Sea as compared to the observations (Fig. 5) which is reflected in the distribution of tropical storms (winds exceeding $17 \mathrm{~m} / \mathrm{s}$ ) from our downscaling runs. In addition, the occurrence of storms exceeding $33 \mathrm{~m} / \mathrm{s}$ (Fig. 6) is excessive in both the Arabian Sea and Bay of Bengal. There are almost four times as many simulated as observed storms of this class. These biases in tropical storm counts in the global model carry through to the hurricane model. That is, the overestimate of storm frequency in the hurricane model simulations is largely predetermined by the over-estimation of such storms in the global model.

Finally, Fig. 7 focusses on even more intense North Indian Ocean tropical cyclones storms, with maximum surface winds exceeding a threshold value of $50 \mathrm{~m} / \mathrm{s}$. The model simulates about $60 \%$ more of such storms than observed, with a more pronounced bias in the Arabian Sea region.

Figure 8 shows the observed and modelled intensity distribution of the storms that were downscaled into the GFDL hurricane model for the North Indian Ocean basin. The simulation shows a pronounced "peaked distribution" bias where there are too few weak and strong storms and too many storms in the middle of the distribution $(35-55 \mathrm{~m} / \mathrm{s})$. The causes of this overly peaked 


\section{OBS - 137 storms}

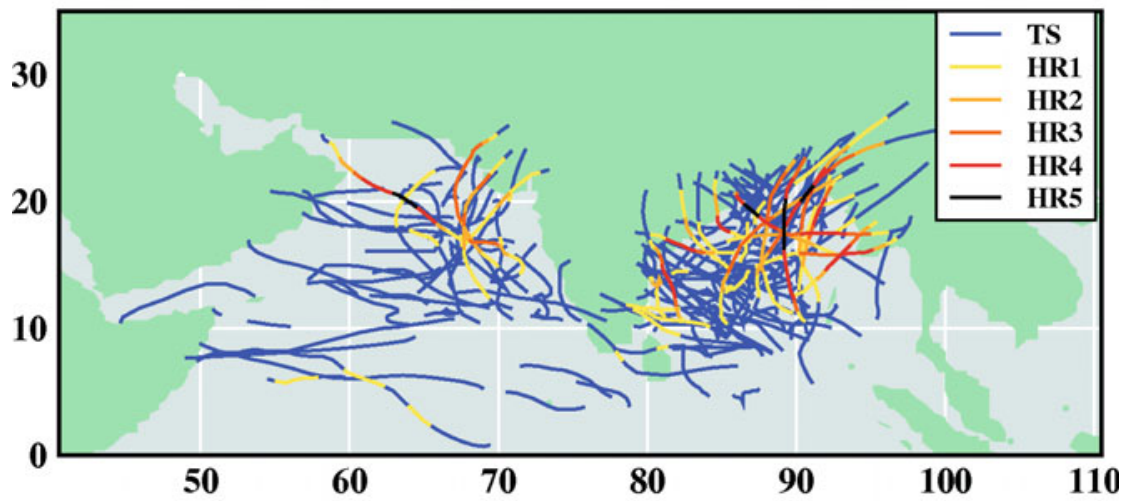

MODEL - 165 storms

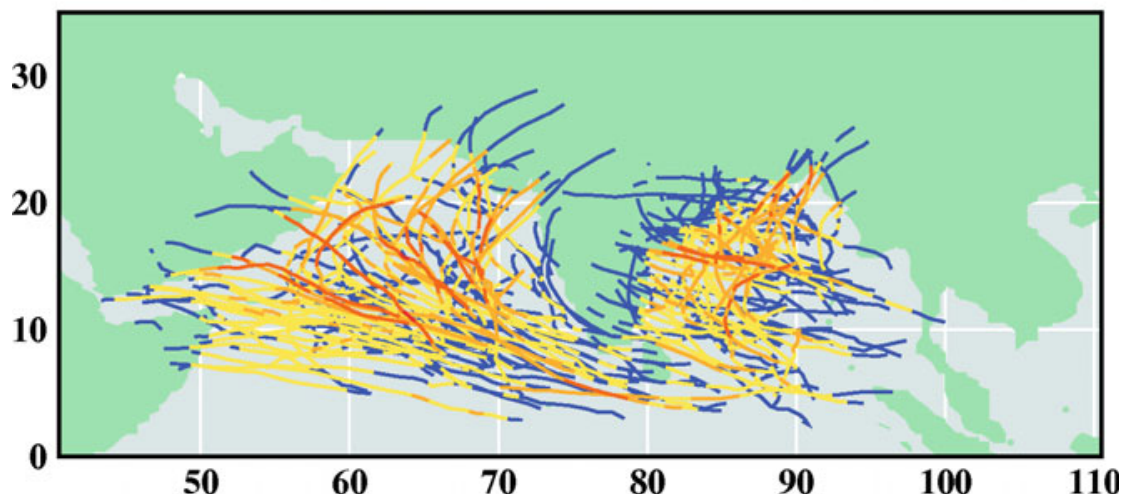

Fig. 5: Tracks of all tropical cyclones with maximum surface winds exceeding $17 \mathrm{~m} / \mathrm{s}$ as simulated for the North Indian Ocean using the GFDL hurricane model to downscale storm cases from a 50-km grid global atmospheric model forced by observed SSTs (1980-2008). TS refers to "tropical storms" with intensities of 17-33 m/s; HR1-HR5 refer to tropical cyclones with intensities exceeding the following thresholds: HR 1: 33 m/s; HR2: 43 m/s; HR3: 50 m/s; HR4: 59 m/s; HR5: 70 m/s.

distribution are still under investigation. Such a distribution is not simulated for the Atlantic basin storms, using the same models, for example.

Although not shown here, an alternative approach that we are pursuing is to use a new GFDL global coupled climate model (GFDL CM2.5) which has an atmospheric model grid spacing of $50 \mathrm{~km}$. In this fully coupled oceanatmosphere climate model, we are able to simulate tropical cyclones up to roughly Category 2 intensity. This model's seasonal cycle of tropical cyclones is fairly reasonable in various basins, although pre-monsoon season tropical storms in the North Indian Ocean are not well-simulated, and too few TCs are simulated in the Atlantic basin. Overall, the model's tropical cyclone activity 


\section{OBS - 41 storms}

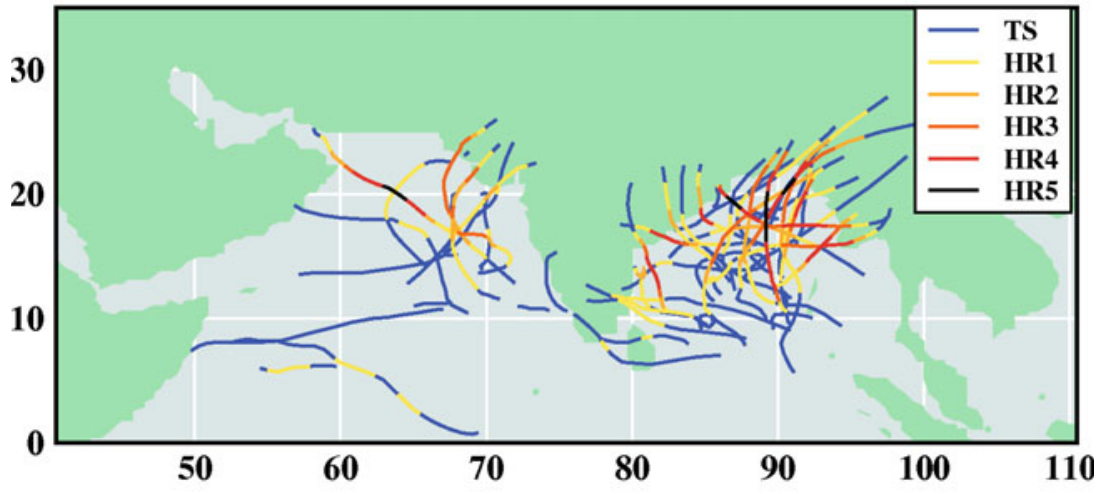

MODEL - 156 storms

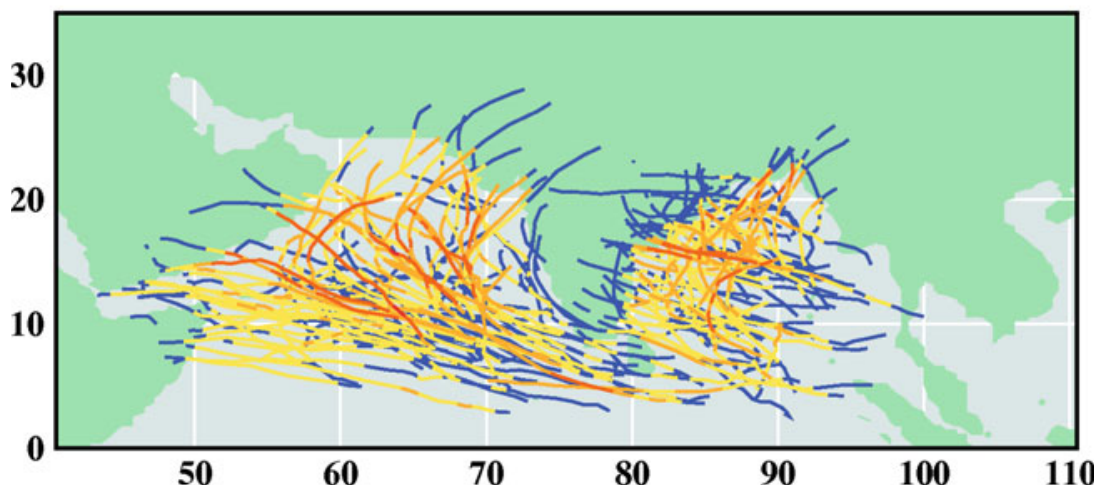

Fig. 6: As in Fig. 5, but for tropical cyclones with maximum surface winds exceeding $33 \mathrm{~m} / \mathrm{s}$ at some point in their lifetime.

response to simulated ENSO variability is quite encouraging, particularly in the Pacific regions, and also to some extent in the Indian Ocean basins.

\section{Summary}

Present-day simulations of intense tropical cyclones in the North Indian Ocean region are being performed and assessed as a preliminary step before climate change simulations being undertaken. While reasonable results have been obtained so far for the North Atlantic and Northwest Pacific basins, the North Indian Ocean simulations exhibit a substantially larger intensity bias, including a distribution of storm intensities that is much more clustered around $\sim 40-50$ $\mathrm{m} / \mathrm{s}$ than is the case for the distribution of observed (JTWC) TC intensities in the region. 


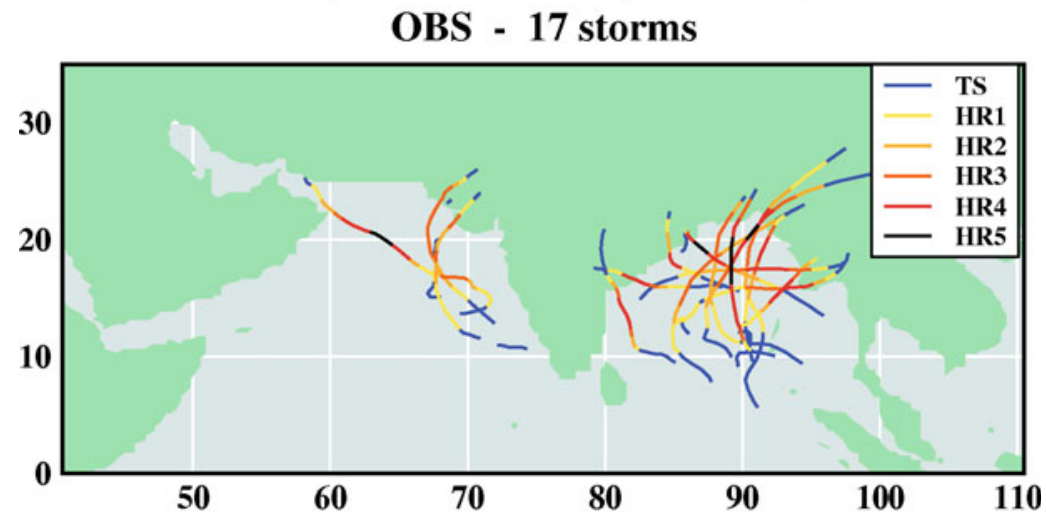

MODEL - 27 storms

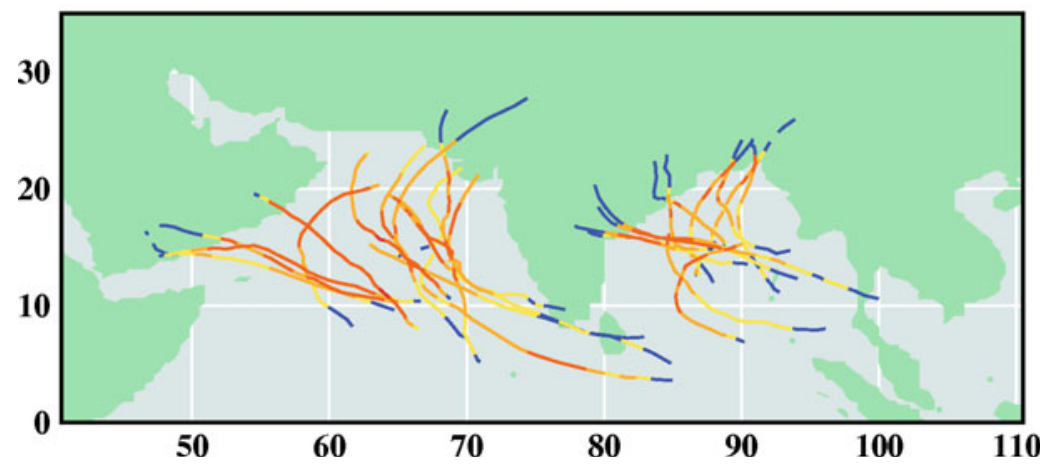

Fig. 7: As in Fig. 5, but for tropical cyclones with maximum surface winds exceeding $50 \mathrm{~m} / \mathrm{s}$ at some point in their lifetime.

\section{Acknowledgements}

We thank the Met Office Hadley Centre and the Climatic Research Unit, Univ. of East Anglia, for making the HadCRUT4 data set available to the research community, and the various modelling groups participating in CMIP3 and CMIP5, and PCMDI, for generously making the model output used in our report available to the community. We acknowledge the Willis Research Network for providing funding support for HSK.

\section{REFERENCES}

Bender, M.A., Knutson, T.R., Tuleya, R.E., Sirutis, J.J., Vecchi, G.A., Garner, S.T. and Held, I.M. (2010). Modeled impact of anthropogenic warming of the frequency of intense Atlantic hurricanes. Science, 327: 454-458. 


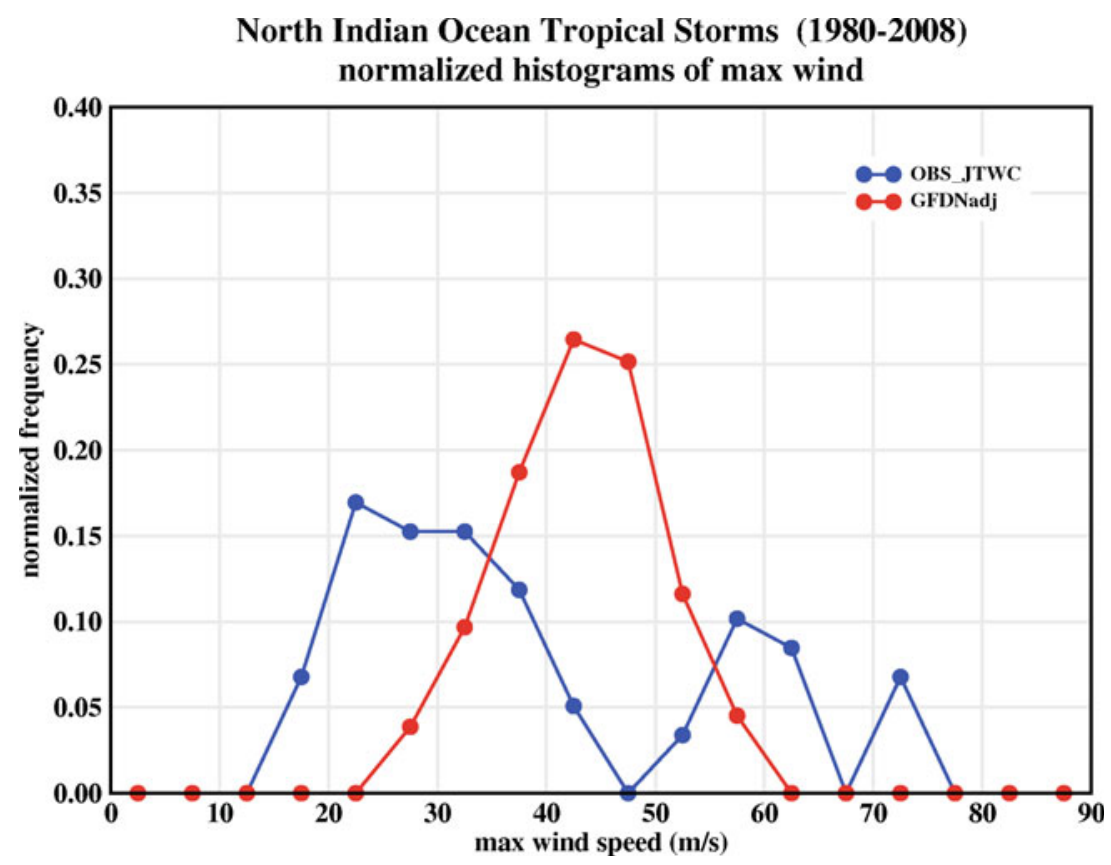

Fig. 8: Distribution of lifetime-maximum surface wind speeds in the North Indian Ocean tropical cyclone observations (JTWC, in blue) and after downscaling simulated storms from a GFDL 50-km grid global atmospheric model into the GFDL hurricane model (red). The distributions have been normalized by the total number of storms (N) so that the shape of the distribution can be more easily compared.

Karoly, D.J. and Wu, Q. (2005). Detection of regional surface temperature trends. $J$. Clim., 18: 4337-4343.

Knutson, T.R., Delworth, T.L., Dixon, K.W. and Stouffer, R.J. (1999). Model assessment of regional surface temperature trends (1949-1997). J. Geophys. Res., 104(D24): 30,981-30,996.

Knutson, T.R. et al. (2006). Assessment of twentieth-century regional surface temperature trends using the GFDL CM2 coupled models. J. Clim., 19: 1624-1651.

Knutson, T.R., Zeng, F. and Wittenberg, A.T. (2013). Multi-model assessment of regional surface temperature trends: CMIP3 and CMIP5 $20^{\text {th }}$ Century Simulations. Submitted to Journal of Climate.

Xie, S.-P., Deser, C., Vecchi, G.A., Ma, J., Teng, H. and Wittenberg, A.T. (2010). Global warming pattern formation: Sea surface temperature and rainfall. J. Climate, 23: 966-986. doi: 10.1175/2009JCLI3329.1.

Zhao, M., Held, I.M., Lin, S.-J. and Vecchi, G.A. (2009). Simulations of global hurricane climatology, interannual variability, and response to global warming using a $50 \mathrm{~km}$ resolution GCM. J. Clim., 22(24): DOI:10.1175/2009JCLI3049.1. 